TURIZAM

Volume 17 , Issue 4

177-184 (2013)

\title{
Berlin: Sustainability and Tour Guides in a Partial Dark Tourism Destination
}

\author{
Asaf Leshem* \\ Received: September 2013 | Accepted: November 2013
}

\begin{abstract}
When guiding in Berlin about the Holocaust or about the Cold War, tour guides often hear the phrase: "I didn't come here for that, but I want to see that as well..." Many of Berlin's 10 Million visitors per year claim to have an attraction towards both the morbid and the lighter side of the city. Following from that popular sentiment it is argued that Berlin can be defined as a Partial Dark Tourism Destination. As such, it is further argued that Berlin is prone to an increase of socio-economic and socio-cultural negative impacts. The premise of the research is that Berlin's tour guides function as a link between the residents of the city and the visitors. The thesis, then, is that tour guides play a role and can contribute to development of social, cultural and economic urban tourism sustainability.

An analysis of tourism impacts and tourists-residents relations is presented, in which the tour guide plays a role in influencing the visitor's behaviour. I conclude that tour guides have greater influence on social, cultural and economic behaviour of the tourist than previously considered, and therefore a potential to enhance sustainable tourism development in Berlin. The significance of this research is in the way it points out to the roles Berlin tour guides play in facilitation of sustainable tourism development in the city. Furthermore, the research shows the ways in which tour guides contribute to increasing responsible tourist behaviour.
\end{abstract}

Key words: Berlin, sustainability, tour guides, dark tourism

\section{Introduction}

The development of Berlin into the fastest growing tourist destination in Europe (Dreger, 2OI3) has largely to do with its dark past. Twenty three years after the fall of the Berlin Wall and the reunification of the city, travellers of all kinds testify to their need to learn about the city's Nazi past and of course of its time divided by two walls with a Death Strip between them. When guiding in Berlin about the Holocaust or about the Cold War, tour guides often hear the phrase: "I didn't come here for that, but I want to see that as well..."

\footnotetext{
* Department of Social Sciences, Humboldt University of Berlin, Faculty of Arts and Humanities III, Unter den Linden 6, 10099 Berlin; Corresponding author: asafleshem@gmail.com
} 
This combination of leisure fun activities with learning of local historical events is what I define here as Partial Dark Tourism Destination. As such, Berlin is not only susceptible to the common social conflicts of many more experienced urban destinations, but also to socio-cultural negative impacts of tourism.

Dark Tourism, a phenomenon explained by Lennon and Foley (2000) as tourists visiting sites associated with war, genocide, assassination and other tragic events. In most cases remembrance and education provide motivation for visitors to travel often great distances to dark tourism destinations. Berlin, as argued above, is a Partial Dark Tourism Destination, thus making it useful for understanding of the tourist tendency to blend pleasure (e.g. going to clubs and shows) with the attraction to morbid (going to tours or museums depicting the darker parts of Berlin's history, i.e. the ruling years of the Nazis and later the DDR).

With the green 'enlightenment' of the past $4 \mathrm{O}$ years, travellers and tourism researchers started being interested not just in the positive economic impacts of the tourism industry, but also in the industry's negative impacts. Since Héctor Ceballos-Lascuráin first coined the term Ecotourism in I983, many scholars followed with further debates and definitions, expanding the field into tourism which takes place in urban areas and to more typologies of tourism. Weaver (I998) and Fennell (I999) were of the first to expend the questions of tourism impact beyond nature areas, shifting the debate rather to the impacts of the industry on five fields: environment, economy, society, culture and education. The latter, although not included in all sustainable and ecotourism definitions is especially pertinent with regards to the niche of dark tourism.

The hypotheses of this research is that A. tour guides can convey, monitor and role-model appropriate visitor behaviour (i.e. inspire social sustainability); B. tour guides can increase visitors' enjoyment of the destination; C. tour guides can influence economic behaviour of the visitor; D. finally, through interpretation, tour guides can expose the visitor to different socio-cultural and historical angles the visitor was previously unaware of.

This research was intended as a preliminary study meant to achieve two goals. The first goal was - following the hypotheses presented above - to find out answers to the following questions: In what ways Berlin tour guides play a role in facilitation of sustainable tourism development? And in what ways tour guides contribute to increasing responsible tourist behaviour in Berlin? Using the results, the second goal was the find out the relevance and usability of such research in order to justify the research and writing of a $\mathrm{PhD}$ thesis.

In addition to eighteen museums focusing on different parts of the city's history, hundreds of tour guides work in the city. In the past three years, researchers started exploring the connection between tour guides, destination interpretation and sustainable tourism development.

In developing a framework for sustainable interpretive guiding, $\mathrm{Hu}$ and Wall (2OI2) suggested that tour guides have the opportunity to teach local history and customs, thus contribute to promotion of sustainability. Similarly, Betty Weiler (Weiler, Kim, 2OII; Weiler, 2OI3) argued that tour guides have the potential to communicate and role model sustainability, including mediating between local residents and visitors.

Tour guides are expected to portray its history to the visitors, with all its intrinsically culturally sensitive information. In some cases the showing of the city's recent history can be directly offensive to residents who experienced events in real time. One such example is the Trabbi Safari. The name alone brings to mind an animal Safari in a nature reserve the likes of the Masai Mara in Kenya, only the animals are replaced by people and their recent past being put on display.

More challenging still are the many types of guided tours, in which guides are asked to explain, often with detailed analysis, about philosophically problematic questions of war, hate, human rights and crimes against humanity. Although majority of the visitors are at an 
age where they already formulated an opinion of Berlin and of Germans (past and present), the argument here is that tour guide have great power in influencing people's perceptions using historical telling from one or more angles.

\section{Sustainability in the context of urban tourism}

In preparations for this study the author spoke to people who never studied ecotourism/sustainable tourism to try to see what it means to them. Answered quickly, most people said that, from general knowledge, sustainable tourism had something to do with environmental impacts and with economic impacts. Although this is not incorrect, this public perception is lacking in the context of the high-speed tourism development of Berlin. It therefore requires focusing of the issues. In the following section the author explored specific situations within the context of sustainable urban tourism development in Berlin.

Perhaps the greatest socio-economic conflict accompanying tourism growth is seen with locals being aware of the negative impacts of the industry without being able to correlate increased visitor numbers with positive impacts. In July $2 \mathrm{OI} 2$ more than one million people visited Berlin, with its population of 3.3 Million (Amt für Statistik Berlin Brandenburg, 20I3). Statistics shows that this trend is only likely to grow. Although many in the city are directly employed in the tourism industry, others cannot see the immediate benefits that tourism and the tourists bring to the city, such as taxes collected from tourism used for improvement of infrastructure. For example, an office worker who lives in Wedding and works in Potsdamer Platz might only notice the longer time it take them to get to work in the tourist season, but will not receive any higher salary in this time. In other words, economic gains from tourist activity are not felt by all residents of the city firstly because they do not benefit directly and secondly because such macro-economic activity (E.g. construction of better roads) is not perceived as a result of gains made from tourism.

There are other ways where negative social impacts are noticed, both by tourists and residents. Since the tourist boom of Berlin old and new Berliners can be heard uttering angry insults at the tourists. In busy streets like central Friedrich Strasse tourists are sometimes pushed by a local person rushing to work, accompanying the push with a slur that usually sounds to the surprised tourist like passing growl. Cyclists, motorists and commuters on the city's elaborate public transport system find themselves swearing at the "stupid tourists that are taking over the city... They are loud and are always standing in the way" (personal communication, 20I3). Such social conflicts become an increasingly common phenomenon.

What makes Berlin into one of the most attractive urban destinations in the world today is the diversity of places to see, attractions and experiences, which are appealing to almost every type of tourist. Visitors come to enjoy an average of I,5OO cultural events that are taking place in the city every day, go to parties, concerts and shows, and enjoy the hundreds of galleries and museums that are spread all over the city. It can be argued that such a great diversity of art and music is a positive cultural impact, partly a result of the growth of the tourism industry. That is to say that with a greater number of potential consumers of culture (with capital C) artists are attracted to live and work in Berlin; Berliners themselves, then, enjoy this inspiring diversity.

Economic impacts of the tourism industry in Berlin are felt in several ways. With the increase of people using the public transportation system there is also more need for maintenance and indeed large scale fixing of trains, tracks, and stations. For example, until recently most stations were not wheelchair accessible. City authorities now understand this and are slowly modernising the stations. Such modernisation process does come with disrupt- 
ing road work. While the necessity of these changes is not disputed by local people, wiggling around between hundreds of construction sites antagonises drivers who feel that the work is done due to constant increase in tour buses appearing in the city.

Improvement of urban infrastructures is relatively easy to justify. Local people argue that in the summer months it is difficult to commute in the city. Furthermore, many people claim they can no longer afford to live in the city centre due to the conversion of many houses to holiday apartments for tourists. The topic of gentrification in the central boroughs of Berlin is a much debated one and is often in the public discourse. Nevertheless it is mentioned here only briefly as it is not in the focus of this study. It is indirectly related due to increased antagonism of old and new Berliners. I argue here that with increased negative feelings towards the tourists, people have hard time to distinguish between issues that tourists cannot control, to behaviours, which can be changed.

Many authors have argued that tourism can also bring such positive economic gains to local communities and improvement of conditions (see for example Weaver, 1998, Fennell, I999). If in the past tourists uses to shop mainly in the famous Ku'Damm Avenue of the west, today businesses in many other boroughs of the city can benefit from the enormous rise in visitor numbers. In a hybrid city of capitalist and socialist systems some of the older Berliners argue that the city is rapidly losing its unique character; becoming too "Americanized". On the other hand, many former East German citizens proclaim satisfaction with the constant building of new shopping malls. Further critique comes from those businesses who still feel that economic gains from tourism are kept to a relatively small amount of hotels, restaurants and other tourist attractions.

The number of arrivals and departures from Berlin airports is another sensitive and vastly debated issue in Berlin, albeit again, not directly related to this study. The city has been trying to close down the functioning and widely loved Tegel Airport. However, the building of the new BER Airport, which is supposed to be able to handle 27 Million passengers per year (Flughafen Berlin Brandenburg, 2OI3), is delayed. In the meantime, one of the many delays is caused by the public debate about the noise levels and hours of flight. Once more, the constant rise in visitor numbers, greatly sought after by the poor city authorities, is not equally desired by locals living in and around future flight routes.

\section{Portrayal of dark tourism and the effect on tourist-resident relations}

One of the main limitations of this study is the sensitivity in the character of a tourism destination which caters to leisure/cultural tourism, has dark history, and is also an urban space where residents are not separated from the tourists. In many instances local people of various ages are exposed to the content tour guides tell the tourists. Bus drivers who understand English hear bits of their own history analysed, often criticised. Neighbours quite often have groups of tourists standing under their windows telling about Nazi times or how things were during the times of the German Democratic Republic. As for the latter, it is worthy of noting that many people from this time see the often not-Berlin born guides telling about their lives from a perspective they are not always happy with. The difficulty here is great, on the one hand maintaining local pride is important for keeping good residents-tourists relations. The risk of an unfair or incomplete analysis of events is to the locals as well as to the tourists. Locals may feel wrongly portrayed, further increasing feeling of antagonism towards tourists and reacting in some way against them. Tourists may be psychologically influenced by what they hear in a negative way, which can diminish their enjoyment of the city. 


\section{Methods and Data}

Over the last four years the author has been working as a tour guide. As such I have been observing tourism and tourist activity in Berlin and the surrounding (including Dresden, Leipzig, Potsdam, and the memorial site for the concentration camp Sachsenhausen). In the process of training, during seminar days or museum excursions, and to maintain quality, guides often observe the work of other guides within their respective companies. This method of working came to be very useful in giving the research subjects a wider perspective to respond on work observed other than their own.

Data was collected in three ways: (I) When possible, conversations with guides during coffee breaks and in meeting points. (2) To supplement the first, questions were sent to guides through emails. (3) In some cases, questions were asked using online chats.

This also allowed the interviewees to respond in their own convenience, and to have a 'conversation like' interview. In support of this Meho (2006) argued in favour of email interviews. He suggests that E-mail interviewing brings the advantage that the researcher can reach research subjects who otherwise would not be available (due to distance or geographical remoteness).

However, email interviews are not without limitations. For one, it lacks visual or non-verbal cues. Furthermore, when answering emails the interviewee may have time to consider their response, review it, and answer what they think is the required answer (ibid.). To some extent online chatting solves a couple of potential interview obstacles. Like email interviews it does not require the interviewer and interviewee to be in the same room (or the same continent for that matter). Moreover, unlike email interviews, chatting interviews are conducted in real time, thus permitting a conversation like interview that is as close as possible to a face-to-face interview. Chatting interviews, though, are similarly limited in the sense that they do not allow the interviewer to probe the interviewee's body language and facial expressions; the very thing that is the advantage of face to face in-depth interviews.

As a preliminary study, part of the aim of the interview was to establish if the tour guides and other tourism stakeholders would find the research problems relevant to their work and to sustainability of tourism in Berlin more generally. For this, interviewees provided not just detailed answers, but further coloured their answers with examples and anecdotes as to why they do what they do and how. Some of these anecdotes are brought here as ethnographic descriptions, through which an analysis of the research question is achieved.

\section{Results}

\section{Guiding Dark Tourism}

More than half of the guides reported that they tell their customers if what they say is their own private opinion, albeit in a casual way without necessarily emphasising it. Two thirds of the guides interviewed said that they do not explain every historiographical research limitation. However, if there is a controversy about the topic, historical findings or accepted theories, then they tell about it.

A known case for the guides is the bombing of Dresden. Guides reported detailing four theories for the allies' reasons for the bombing, and for its timing. Although explaining that 
the allies did not bomb army targets they still received the rare reaction that "they [the Germans] deserved it!", to which one guide replied that the fire storm could not distinguish between Nazis and anti-Nazis. Nevertheless, most guides concluded that it is more important for them not to risk antagonising the tourists.

An interesting story told by an experienced guide: "when standing near what use to be Hitler's bunker many tourists ask me questions like: did Hitler have any Jewish blood in him? Was he gay? These are all easy to deal with; I find if one sticks to what we do know and don't try to embellish, then your credibility is respected".

A common occurrence has been identified by Israeli tour guides when bringing groups to the Vila where the Wannsee Conference took place. The guides reported that when leaving the museum, while walking to the exit, tourists always asked the same question: "how can you live here?!" [in Berlin]. The guides felt they were put on the spot defending something which has little to do with what the tourist saw and read in the museum. The question the guides posed was what answer am I supposed to give the tourist knowing the sensitive psychological state they are in right after leaving the museum?

In terms of education as part of the visitor's tourist experience it is worthwhile to briefly look at the level of knowledge visitors arrive with. Tour guides said they consider the accuracy of her the information given to their tourists according to how knowledgeable they are to begin with. Accordingly, if the tourists are 'stupid looking' they will not distinguish between facts and research problems, nor will they raise challenging philosophical questions. In such case then, they only tell the tourists "what we know for sure".

In other cases tourists often proclaim higher than basic knowledge of the Holocaust or of East German times. Their stated goal is to deepen their knowledge of the historical era they are interested in. Unanimously, all guides said that in that case they feel pressure to bring more historical facts than the tourist knows. For guides, this is also a good thing, as they are happy to hear 'good questions' in a tour, consequently bringing the analysis and discussion in a tour to a higher level.

In many cases this type of tourist are of an older age, and, as guides suggested, mix emotions with facts. Several of the guides interviewed said that with such tourists they face the challenge of being sensitive to their customer's feelings and at the same time staying true to what they know, even if the facts are not so pleasant to hear. A common example is the question asked by many tourists: "why the German people didn't resist the Nazis?" One guide explained: I can of course feed their prejudice and say something like "Germans are disciplined and are not in the habit of resisting their governments", or even suggest that they all supported the Nazis. However, I usually prefer to "make life difficult for them [the tourists]" by presenting facts and numbers, then ask them what they would have done if they were citizens of a totalitarian state which kills people who protect its persecuted minorities? The guide added that "I never tell them what I would have done, nor that I want them to tell me the answer, only that it's important to think about that".

\section{Guides responding on teaching local customs and social values}

When comparing to other major European cities, many tourists claim that Berlin is very spacious. For local people, though, the feeling can be quite different, especially at the tourist high season of July and August. For reasons of climatic adaptation, construction work is mostly done in July when the city absorbs more than one million visitors in addition to resident population. As a result of that there are frequent conflicts between bus drivers, car drivers, cyclists, and pedestrians. Most guides said that they often witness the dangers to tour- 
ists from drivers, who on their part are angry with tourists walking around oblivious to their surroundings (Urry, 20O2). Protecting the tourists was the first thing that most guides said.

As for bicycle lanes, here I vocalise the importance of staying off them because of the safety of my customers. I think it's important to point out cultural nuances, and that our customers will find it very interesting. Having said that, I never tried to 'teach' or push local cultural elements.

At best, cyclists - who often race thought the city's long avenues at top speed - are annoyed by tourists "walking with their heads to the sky". A worst scenario is an accident that can be caused when tourists are not aware of the special lanes.

Another common cultural misunderstanding takes place on the train platform of the many busy stations of the city. Whereas mostly it can be said that it is cultural knowledge in Berlin to wait for people to leave the train before entering, visitors from countries without similar public transport system are often seen standing at the doors creating congestion and delays. A short clarification can solve this and increase visitor enjoyment of the destination. When, in some of the interviews, this issue came up, guides usually said that it would be a smart thing to do; regretfully, though, they cannot always explain that in time because of practical reasons.

I talk about cultural elements but unfortunately I don't teach everything I would like to teach (for example how to tip waiting staff in Berlin). I sometimes hint something, which they normally don't understand...

Tipping is another local customs that is quite different from many other countries in the world. In Berlin is it not customary to leave a tip for waiters on the table when walking out of the restaurant. Instead, diners tip directly to their waiter or waitress thanking them with the amount they want to tip (depending on weather they were happy with the service or not). It is likely that most service staff are aware of this cultural difference and are therefore not too bothered by it. Nevertheless, they appreciate it when tourists respect the local custom. In a recent tour this was explained to the tourists who offered their own critique: tipping directly, they said, would make them feel awkward, as if they give money to a servant. Having said, they were happy to learn something new about the local culture.

\section{Conclusion}

Berlin, as a partial dark tourism destination is at high vulnerability to various sorts of negative impacts of the tourism industry. By relating information tour guides already function as a link to sustainable urban tourism development in Berlin. However, as testified by the guides themselves, any initiative done is done as part of their own personal guiding style.

As previously explained, one of the aims of this preliminary study is to examine the interest tour guides and tourists have for the topic; its relevance to tourism development and its usability to society in Berlin in general. From planned interviews with tour guides and from informal conversations with other stakeholders it is concluded that there is a room for a research on much bigger scope on the same issue. In addition to that, it is suggested that there is a long term need for deeper understanding of the type of sustainability that is not tangible, and which impacts collective memory and the culture of remembrance. In other 
words, and more specifically, a research that will focus solely on the topic of portrayal and interpretation of historical events in Berlin and other dark tourism destinations.

\section{References}

Amt für Statistik Berlin Brandenburg, (2OI3). Pressemitteilung Nr. 2IO vom 25. Juli $2 \mathrm{OI3}$. Accessible at https://www.statistik-berlin-brandenburg.de/pms/20I3/I3-O7-25a.pdf. 3.8.2OI3.

Dreger, K., (20I3). Berlin - the Fastest Growing Destination in Europe. Berlin, visitBerlin / Berlin Tourismus \& Kongress GmbH.

Flughafen Berlin Brandenburg, (2OI3). The airport in brief. Accessible at http://www.berlin-airport.de/en/travellers/the-new-airport/the-airport-in-brief/. 3.8.2OI3.

Foley, M., Lennon, J.J. (2OOO). Dark Tourism: The Attraction of Death and Disaster. Continuum, London.

Fennell D., (1999). Ecotourism. Routledge, Oxon.

$\mathrm{Hu}$ W., Wall G. (2OI2). Interpretive guiding and sustainable development: A framework. Tourism Management Perspectives 4, 80-85.

Meho I.L. (2006). E-Mail Interviewing in Qualitative Research: A Methodological Discussion. Journal of the American Society for Information Science and Technology, 57, IO, I284-I295.

Pereira E., Hoffmann O., Horvati E., Mykletun R., (2OI2). Innoguide: A comparitive Analysis of guide training programmes in 8 participating countries/regions. Peter de Vilde, Brussels.

Stone P., Sharpley R. (2008). Consuming dark tourism: a thanatological perspective. Annals of Tourism Research, 35, 2, 574-595.

Weaver D.B., (1998). Ecotourism in the less developed world. CAB International, Wallingford, Oxon.

Weiler, B., (2OI3). 'From memorable to meaningful: tour guiding as a tool for sustainable tourism', keynote address presented to 3rd International Research Forum on Tour Guiding, Breda, Netherlands, 4-6 April.

Urry, J., (2002). The Tourist Gaze. SAGE Publications Ltd, London.

Yuill, S.M., (2003). Dark Tourism: Understanding Visitor Motivation at Sites of Death and Disaster. Master's Thesis. Texas A\&M University. 